\title{
PENGENALAN MATERI DASAR BAHASA INGGRIS BAGI ANAK-ANAK USIA DINI DI PULAU MECAN, SEKANAK RAYA, BELAKANG PADANG, BATAM
}

\section{INTRODUCING ENGLISH BASIC MATERIALS FOR EARLY CHILDREN AT MECAN ISLET, SEKANAK RAYA, BELAKANG PADANG, BATAM}

\author{
Erwin Ashari \& Shalehoddin \\ Universitas Riau kepulauan \\ erwinashariharianja83@gmail.com,
}

\begin{abstract}
Abstrak
Kegiatan ini bertujuan untuk memberikan menstimuli minat dan motivasi anak-anak anak usia dini dalam belajar Bahasa Inggris yang merupakan salah satu bahasa Internasional. Dengan memberikan materi yang dasar dan dengan menggunakan metode dan pendekatan yang sesuai maka minat belajar mereka pun semakin tumbuh dengan baik. Adapun aspek yang paling ditekankan dalam kegiatan ini adalah pada penguatan dan pemerkayaan kosa kata dengan memberikan contoh di sekitar mereka. Penguatan pada cara pengucapan dilakukan dengan cara memberikan contoh pengucapan dan diucapkan berkali kali melalui metode percakapan sederhana dan irama nyanyian yang disadur. Dalam kegiatan ini, Small Group Discussion digunakan yakni membagi peserta yang berjumlah 25 orang kedalam 5 group kecil. Dengan menggunakan metode yang bervariasi seperti menggabungkan Game Dan Sing Songs, dihasilkan dampak yang positif, dimana pada awalnya peserta kegiatan masih terlihat malu dan takut namun pada akhirnya menjadi lebih berani dalam menyampaikan pendapat. Dampak lain yang terlihat adalah meningkatnya rasa kepercayaan diri mereka setelah digunakan pendekatan khusus yakni dengan memberikan kata pujian pada setiap jawabann yang benar dan kurang tepat. Untuk jawaban yang salah diberkan juga pujian yang bersipfat pujian terhadap keberaniannya.
\end{abstract}

Kata Kunci; Pendidikan Anak Usia Dini, Stimuli Minat dan Motivasi, Penguatan Kosa Kata dan Pengucapan.

\begin{abstract}
This activity aims to stimulate the interest and motivation of early children on learning English as one of the International languages. By providing basic material and using appropriate methods and approaches, their learning interests are growing well. The most emphasized aspects on this activity were the strengthening and enrichment of vocabulary by giving examples around them. And to strengthen pronunciation, it was emphasized by giving examples of word pronunciation and being pronounced many times through simple conversation and adapted rhythmic. In this activity, Small Group Discussion was used, which divided 25 participants into 5 small groups. Byusing mixed methods such as combining the Game and Sing Songs methods, a positive impact was occurred, at first the participants of the activity still looked shy and scared but at the end of activity they became more brave on expressing their opinions. Another effect that was seen was the increase of their selfconfidence after using a special approach that was by giving praise words to every correct and incorrect answers. For the wrong answers, praise was given for the praise of his courage.
\end{abstract}

Keywords; early children Education, Interest and Motivation Stimulilus, Vocabulary and Pronunciation Strengthening. 


\section{PENDAHULUAN}

Pulau Mecan adalah pulau kecil berpenghuni yang berada pada garis terdepan Negara Indosesia dan perbatasan langsung dengan Negara Singapura dan berdasarkan administrasi termasuk Kelurahan Sekanak Raya, Kecamatan Belakang Padang-Kota Batam. Pulau Mecan didiami oleh sekitar kurang 50 Kepala Keluarga (KK) dan dikepalai oleh RT (Rukun Tetangga) dan hampir $100 \%$ bermata pencarian sebagai nelayan. Kondisi ekosistem Pulau Mecan termasuk ekosistem yang beragam seperti mangrove, lamun dan terumbu karang dalam kondisi dalam rehabilitasi karena mengalami kerusakan yang disebabkan karena katidaktahuan masyarakat dalam pemanfaatan secara lestari dan berkelanjutan. Di daratan Pulau Mecan, hutan masih tergolong hijau, dan di dekat pemukiman warga banyak tumbuh pohon kelapa yang produktif, sedangkan struktur tanahnya adalah berpasir pada daratan dan juga pada sisi pantainya. Dengan keadaan tersebut maka Pulau Mecan sangat potensial menjadi daerah wisata alam.

Pendidikan yang merupakan kebutuhan dasar manusia, masih terkendala di Pulau Mecan. Pemerintah telah membangun sekolah pembantu di Pulau Mecan, namun tidak berjalan dengan baik dikarenakan jumlah quoata siswa yang tak terpenuhi dan juga minimnya tenaga pengajar, sehingga anak-anak di Pulau Mecan bersekolah di pulau sebelahnya yaitu Pulau Sarang, sedangkan untuk tingkat Sekolah lanjutan, SMP dan SMA/K yakni ni Belakang padang, Ibu kota kecamatan. Jalur transportasi ke Pulau Sarang disediakan oleh pemerintah untuk antar dan jemput siswa pergi dan kembali ke Pulau Mecan. Selain itu kompetensi tim pengajar, sarana dan prasarana penunjang pembelajaran seperti buku teks maupun kamus Bahasa Inggris baik bagi guru Bahasa Inggris maupun untuk siswa menjadi kendala dalam peningkatan keberhasilan dalam pembelajaran Bahasa Inggris(Sudrajat, 2015)(Radjab \& Syarif, 2009), hal ini juga menjadi kendala bagi peserta didik di Pulau Mecan.

Melihat antusias siswa dalam belajar, dan didukung oleh potensi daerah yang sangat bagus untuk jadi tujuan wisata, maka kami sangat tertarik untuk melakukan pengajaran 
terkait pengenalan dasar Bahasa Inggris bagi Anak-naka usia dini di Pulau Mecan. Walaupun pada dasarnya anak usia dini berbeda degan orang dewasa dalam belajar dan mencari ilmu, sebab meraka masih lebih ingin bertemu, bergabung dengan teman seusianya dan bermain asyik, oleh karena itu pelajar kepada anak usia dini harus menggunakan strategi khusus atau yang berbeda dengan pelajarusiadewasa (Fillmore, dkk., 1979). Jadi, dalam kegiatan pengabdian ini, tim juga melakukakukan stategi khusus juga, yakni menggunakan strategi pembelajaran yang diarahkan kepada pencapaian kompetensi dan rasa percaya diri (confidence) (Krashen (1981). Setelah mereka memiliki rasa percaya diri maka kompetensi itu bisa dikembangkan maka pembelajaran sesungguhnya bisa diterapkan. Sehingga pemahaman Bahasa Inggris tidak hanya sebatas hapalan tetapi sudah mencapai pada makna, guna, aturan dan aspek lainnya dalam komunikasi Richard dan Schmidt (2002). Sebab penguasaan bahasa asing akan tercapai dengan pendekatan lintas linguistik Horst (2010), maka metode Contextual Teaching and Learning (CTL) juga diterapkan sebab metode ini dapat memberikan dampak yang positif bagi peserta didik dalam mempelajari dasar-dasar bahasa inggris untuk dapat diaplikasikan dalam berkomunikasi sehari-hari secara sederhana dan berterima (Pohan, 2017). Dalam pengabdian ini, tim melakukan praktek langsung, dengan melakukan penekanan pada pengucapan Bahasa Inggris dengan mengunakan bantua alat peraga lainnya. Hal ini dilakukan karena anak- anak usia dini dapat memaknai suatu bahasa tanpa harus menerjemahkan satu-persatu kata-kata dan juga menceritakan kembali apa yang telah mereka lakukan atau dengar (Clark (1990); Scott \& Ytreberg (1992), dan Halliwel (1994 dalam Sudrajat ; 2015).

\section{METODOLOGI}

Metode pelaksanaan kegiatan pengabdian ini dilakukan beberapa tahapan yaitu persiapan dan pembekalan, pelaksanaan kegiatan dan rencana keberlajutan kegiatan. Persiapan dan pembekalan

Persiapan dan pembekalan

Dalam tahapan ini ada bebarapa mekanisme yang dilakukan seperti

1. Koordinasi dengan LPPM Universitas Riau Kepulauan untuk menyampaikan dan melaporkan rencana kegiatan yang akan dilaksanakan di Pulau Mecan, adapun tujuan dari koordinasi ini adalah untuk memperoleh surat tugas pengabdian dari 
LPPM Universitas Riau Kepulauan dan juga memberikan informasi kepada Universitas melalui LPPM tentang data-data pelaksanaan pengabdian masyarakat.

2. Koordinasi dengan ketua RT Pulau Mecan, dalam hal ini, saya bersama tim melakukan survey lokasi ke Pulau Mecan setelah melakukan koordinasi dengan ketua LPPM Universitas Riau Kepulauan, adapun tujuan dari koordinasi ini adalah untuk sekaligus menyampaikan maksud dan tujuan pengadaan kegiatan pengabdian di Pulau Mecan agar semua hal yang bersifat teknis bisa terpenuhi. Dengan adanya koordinasi dengan Ketua RT Pulau Mecan maka akan memudahkan tim memperoleh informasi yang dibutuhkan untuk pelaksanaan kegiatan di lapangan. Dalam hal ini, bapak ketua RT Pulau Mecan menyambut baik kedatangan kami dan juga program yang kami rencanakan.

3. Observasi lapangan tentang sasaran kegiatan. Setelah memperoleh dukungan dari ketua RT Pulau Mecan, Tim melakukan penjajakan ke masayrakat dengan di dampingi oleh ketua RT Pulau Mecan.

4. Perekrutan mahasiswa yang ikut terlibat dalam kegiatan. Dalam tahapan ini, tim melakukan perekrutan yang cukup ketat dalam menjaring mahasiswa yang terlibat dalam pengabdian ini. Alasan yang mendasar adalah bahwa transportasi ke Pulau Mecan masih menggunakan transportasi yang sederhana atau yang biasa disebut masyrakat sekitar dengan sebutan "Pogpong”. Selain itu daerah mecan juga masih sulit dalam hal jarngan komunikasi, dimana jaringan komunikasi antara telkomsel Indonesiadengan SingTel Singapura masih sering tumpang tindih sehingga terkadang sinyalpun secara otomatis roaming Internasional.

5. Pembekalan bagi mahasiswa yang ikut terlibat dalam kegiatan. Setelah mahasiswa terpilih dari perekrutan, maka semua mahasiswa mengikuti pembekalan sosial budaya dan materi ajar yang akan diajarkan di Pulau Mecan.

Sedangakan Materi persiapan dan pembekalan meliputi

1. Etika pergaulan, bersosialisasi dan pendekatan mahasiswa kepada peserta kegiatan (anak- anak berusis 4-12 Tahun). Hal ini ditekankan karena kehidupan di Pulau Mecan berbeda dengan kehidupan di daerah urban. Artinya adat melayu masih kental di Pulau Mecan. 
2. Peran komunikasi dalam pelaksanaan program, maksudnya adalah memberikan gambaran cara berkomunikasi kepada mahasiswa dengan masyarakat di Pulau Mecan yang merupakan masyarakat Melayu yang sangat terkenal dengan kesantunan dan tata keramanya.

3. Latihan penyusunan rencana program, maksudnya adalah memberikan masukan dan pelatihan bagaimana menstrategi suatu materi yang akan disampaikan pada peserta didik di Pulau Mecan, sebab fasilitas dan alat bantu pengajaran masih minim dan hampir tidak tersedia di Pulau Mecan.

4. Deskripsi tugas. Dalam deskripti tugas, maka mahasiswa dibagi menjadi lima kelompok, artinya ada dua orang mahasiswa di setiap pertemuan/ hari kegiatan. Hal ini juga dilakukan agar tidak terjadi tumpang tindih materi yang diajarkan, atau agar tidak terjadi pengulangan materi pada pertemuan selanjutnya.

Kegiatan pengabdian ini dilakukan selama tiga hari yakni mulai tanggal 23 Juli sampai dengan 25 Juli 2018 yang dimulai pada jam 13.30 Wib sampai dengan jam 15.30 Wib. Sasaran dalam hal ini dimaksudakan adalah peserta kegiatan. Sesuai dengan judul kegiatan yakni Pengenalan Dasar Bahasa Inggris bagi Anak-naka Usia Dini di Pulau Mecan, maka peserta kegiatan adalah seluruh anak-nak berusia 4- 12 tahun yang ada di Pulau Mecan. Adapun jumlahnya adalah; 25 orang. Mengingat transportasi ke Pulau Mecantidak terjadwal dengan baik, maka setiap keberangkatan tim selalu berangkat bersama-sama. Awalnya berkumpul di Universitas Riau Kepulauan jam 10.00 WIB, selanjutnya berangkat bersama sama ke Pelabuhan domestik di Sekupang, lam perjalanan menuju ke pelabuhan adalah sekita 45 menit. Setelah sampai di pelabuhan maka tim akan naik Pongpong yang disewa pulang pergi dari pelabuhan Sekupang ke Pulau Mecan dan sebaliknya, selama 60 menit.

Materi ajar

Mengingat peserta didik adalah masih di tahap pemula, maka materinya pun disesuaikan dengan materi dasar dalam pembelajaran Bahasa Inggris, adapun materinya adalah; noun, adjective, verb, adverb dan greetings yang disadur dari beberapa sumber yakni dari buku yang ditulis oleh (Hancock, 1998), (Greenbaum \& Nelson, 2002), (Brown, 2004), (Dykes, 2007), (Seaton \& Mew, 2007), (Folse, Solomon, \& Smith-Palinkas, 2008), dan (Mcnally \& Kennedy, 2008). Dalam penyampaian materi, selalu mengutamakan penekanan pada kosakata, pengucapan, tata bahasa sederhana, dan percakapan sederhana agar lebih 
mudah dipahami dan dikuasai oleh peserta didik (M.Yamin, 2017). Penguatan pada kosa kata Bahasa Inggris dapat membuat daya tarik peserta didik untuk mempelajari Bahasa Inggris lebih meningkat (Firdausia, 2016) dan (Radjab \& Syarif, 2009) Penguatan pada pengucapan dilakukan karena banyaknya bunyi Bahasa Inggris yang tidak ada dalam bahasa Indonesia (Tiono \& Yostanto, 2008), sehingga pelapazan bunyi ini perlu ditekankan dan dilatihkan kepada pembelajar pemula. Metode yang digunakan adalah metode berbasis Game, sebab metode berbasis game sangat efektif dalam pembelajaran tingkat sekolah dasar (Sudrajat, 2015). Selain metode bermain, melauli metode Singing bisa menjadi strategi yang baik untuk memperkenaljkan Bahasa Inggris kepada anak anak (Muzammil, 2017).

\section{PEMBAHASAN}

Dalam pembelajaran ini, tim menggunakan metode Group Discussion, artinya tim membagi peserta didik menjadi kelompok kelompok kelompok kecil yang mana setiap kelompok dipandu oleh satu orang tutor. Selain itu, metode Demonstrasi dan Practice serta metode Contextual Teaching and Learning (CTL) adalah metode yang digunakan, artinya setiap peserta harus mengucapkan ulang apa yang diucapkan oleh tutor. Dalam proses pembelajaran materi Nouns ini, terlihat ada sekitar 10 orang peserta yang mencolok, artinya mereka angat berani dan dapat mengikuti pembelajaran dengan cepat, bahkan terkadang terjeadi rebutan mengacungkan tangan dalam menjawab pertanyaan dari tutor di menit-menit akhir pembelajara. Sedangkan terkait materi, para tutor menekankan pada kata benda yang mereka kenal secara konkrit atau sering mereka jumpai, sehingga memudahkan mereka untuk mengingatnya, apalagi tutor memberikan trik khusus dalam mengingat terjemahan kosakata yaiutu dengan metoe persamaan huruf.

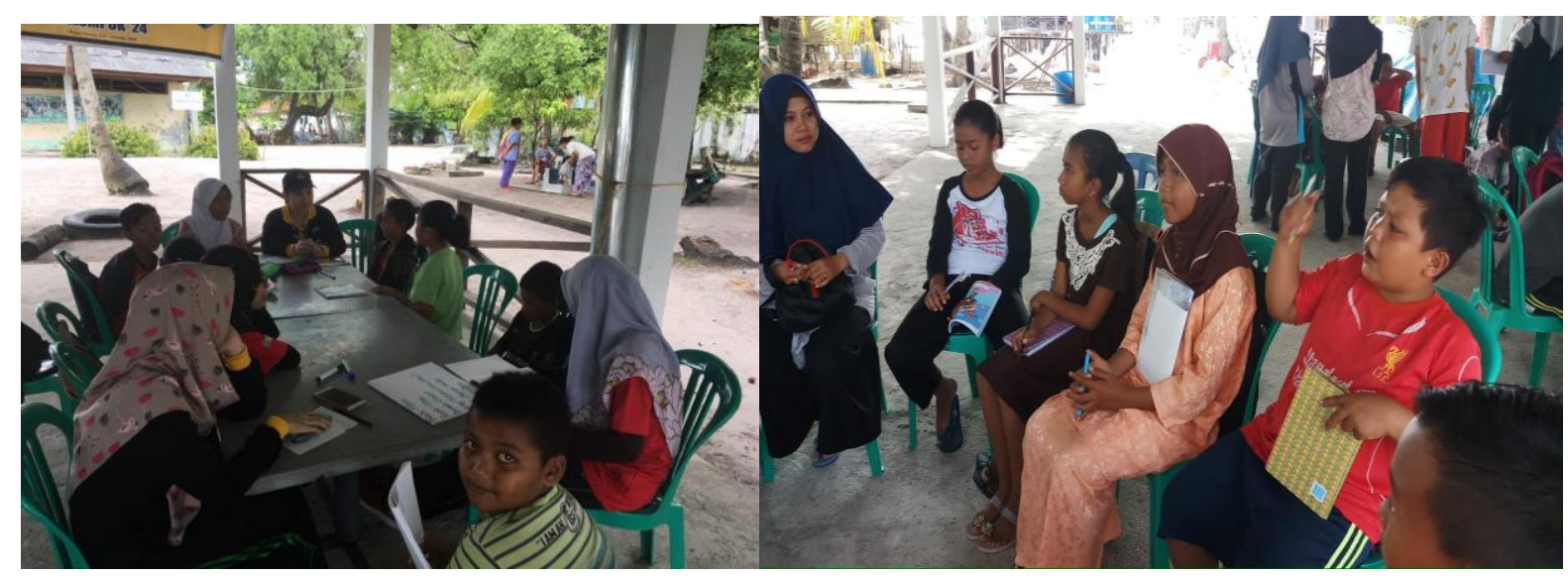


Figur 1. Foto Pertemuan Pertama dengan Materi Noun.

Dalam pembelajaran pada pertemuan kedua , tim tetap menggunakan metode Group Discussion, hal ini disebabkan oleh lokasi pembelajaran atau sanggar yang terbuka dan tidak dialiri oleh arus listrik sehingga sulit memnggunaka media ajar seperti projector dan papan tulis. Selain itu, dengan lokasi yang terbuka seperti itu, maka tentu dibutuhkan volume suara yang lebih kencang, maka disiasati denga menggunkan metode berkelompok sehingga jarak antara tutor dan peserta berdekatan sehingga suara tutor bisa didengar oleh peserta dengan jelas dan sebaliknya. Pada pertemuan ini, jumlah peserta yang hadir bertambah. pada pertemuan pertama peserta yang hadir berjumlah adalah 15 orang, namun pada pertemuan kedua ini bertambah menjadi 25 orang, artinya semua peserta hadir. Belajar dari pembelajaran sebelumnya yang menggunakan metode Demonstrasi dan Practice serta metode Contextual Teaching and Learning (CTL) maka Tim mencoba menambahkan metode tambahan yakni dengan menggunaka strategi baru yang lebih menarik, yakni dengan metode bermain atau Game. Dari pantauan kami, dengan menggunakan metode permainan dalam pembelajaran adjectives ini, maka siswa terlihat lebih menjiwai pembelajaran dalam lebih menikmati, hal ini terlihat di menit-menit pembelajaran bahwa para peserta bisa mengulang kembali apa yang disampaikan oleh tim, da rasio kesuksesannya terkategorikan pada level memuaskan.

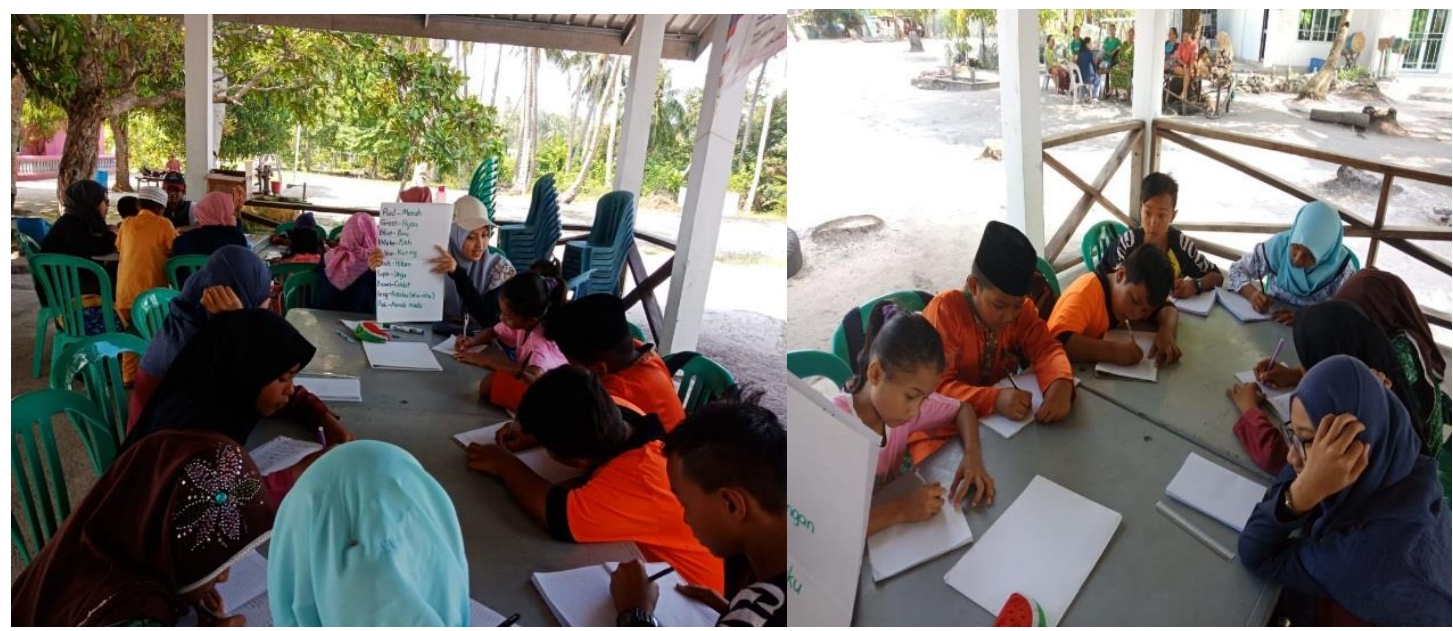

Figur 2. Foto Pertemuan Kedua dengan Materi Adjectives 
Dalam pembelajaran ini, tim tetap menggunakan metode Group Discussion, hal ini disebabkan oleh lokasi pembelajaran atau sanggar yang terbuka dan tidak dialiri oleh arus listrik sehingga sulit memnggunakan media ajar seperti projector dan papan tulis. Pada pertemuan ketiga, jumlah peserta yang berjumlah 25 orang. Pada pertemuan ini, tim tutor membahas materi Verbs. Dalam pembelajaran ini, tim tutor tetap menggunakan metode bermain atau Game. Kali ini pembelajaran dibuat lebih mengarah kepada praktek pengucapan dan perlakuan, (metode Demonstrasi dan Practice serta metode Contextual Teaching and Learning (CTL) )dengan menggunakan seperti pantonim maka peserta kegiatan lebih ceria dalam belajar tersebut. Selain itu dengan mengabungkan dengan Small Group Discussion maka awalnya peserta didik terlihat serius dalam merumuskan Clue dari kata yang harus ditebak oleh kelompok lain dan hasilnya sungguh memuaskan dimana setiap peserta sangat bersemangat.

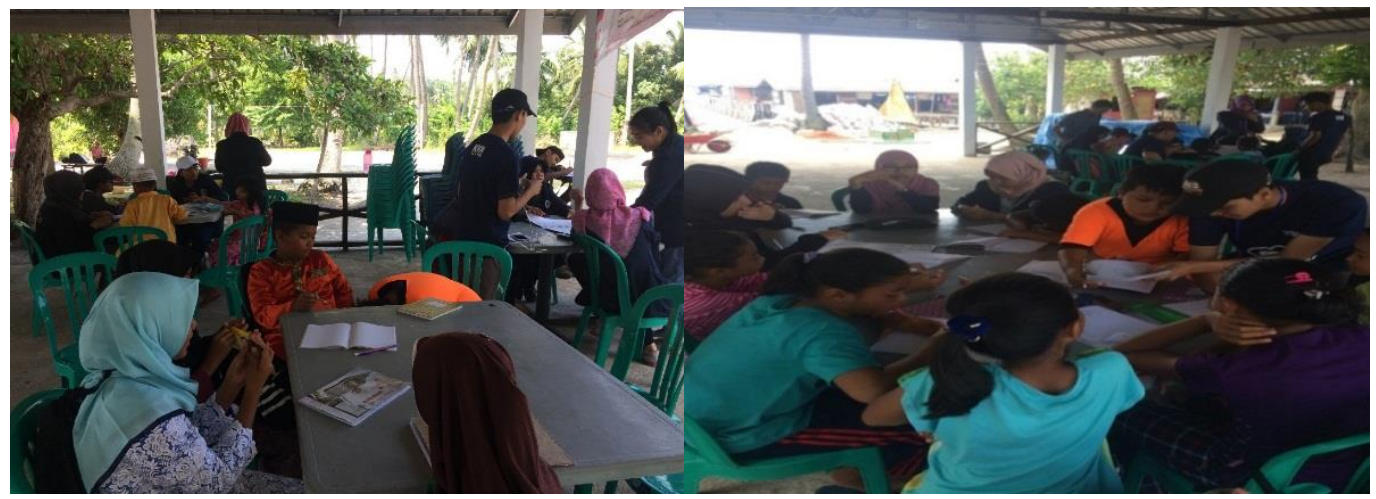

Figur 3. Foto Pertemuan Kedua dengan Materi Verbs

\section{KESIMPULAN DAN SARAN}

- Minat belajar Bahasa Inggris pembelajar usia dini dapat meningkat dengan signifikan dengan menggunakan metode dan pendekatan yang sesuai. Mengingat usia mereka adalah usia bermain maka dengan metode bermain dapat digunakan sehingga di saat proses belajar mengajar ttersebut mereka sangat semangat dan merasa tidak terbebani. Selain itu dengan menggunakan metode bergroup kecil atau small group discussion dan dengan dibantu oleh para tutor yang selalu siap 
membantu memecahkan kendala yangmereka hadapai maka mereka lebih merasa dihargai dan terfasilitasi dengan baik.

- Setelah pelaksanakan pengabdian ini, kami melihat bahwa anak-anak di Pulau Mecan sangat senang dan bersemangat dalam belajar Bahasa Inggris. Dengan pola seperti ini, maka sangat mudah mentransferkan ilmu Bahasa Inggris kepada peserta didik. Dengan menggunakan metode yang bervariasi sesuai dengan tema materi maka pembelajaran akan lebih menarik, seperti metode praktek dan metode bermain. Metode ini bisa memberikan stimuli yang sangat besar kepada siswa dalam belajar Bahasa Inggris.

\section{REFERENSI}

Brown, G. (2004). The Grammar of English Grammars. London: Karl Hagen Proofreading Publisher.

Dykes, B. (2007). Grammar for Everyone. Victoria: Acer Press.

Firdausia, Z. (2016). MAKE A MATCH: PEMBELAJARAN KOOPERATIF DALAM PENGENALAN BAHASA INGGRIS ANAK KELOMPOK B DI PLAY GROUP \& KINDERGARTEN. Skripsi; Pendidikan Guru Pendidikan Anak Usia Dini, Fakultas Ilmu Pendidikan, Universitas Negeri Semarang, Semarang.

Folse, K. S., Solomon, E. V., \& Smith-Palinkas, B. (2008). Top 20 - Great Grammar for Great Writing - Book.pdf(2nd ed.). London: Sherrise Roehr.

Greenbaum, S., \& Nelson, G. (2002). An Introduction to English Grammar (2nd ed.). London: Pearson Education Limited.

Hancock, M. (1998). Singing Grammar. Cambridge: Cambridge University Press.

M.Yamin. (2017). METODE PEMBELAJARAN BAHASA INGGRIS DI TINGKAT DASAR M. Yamin (Dosen Program Studi Pendidikan Guru Sekolah Dasar (PGSD) FKIP Unsyiah). Jurnal Pesona Dasar, 1(5), 82-97.

Mcnally, L., \& Kennedy, C. (2008). Adjectives and Adverbs. Oxford: Oxford University Press.

Muzammil, S. (2017). Pengenalan bahasa inggris kepada anak usia dini. RAHEEMA: Jurnal Studi Gender Dan Anak, 1(1), 164-169.

Pohan, A. E. (2017). PROGRAM PELATIHAN BASIC OF ENGLISH TERHADAP ANAKANAK SISWA SEKOLAH DASAR DI SD N 004 SAGULUNG. Minda Baharu, 1(1), 
$7-14$.

Radjab, D., \& Syarif, H. (2009). PELAKSANAAN PEMBELAJARAN BAHASA INGGRIS DI SEKOLAH DASAR KOTA PADANG. Lingua Didaktika, 3(1), 32-45.

Seaton, A., \& Mew, Y. H. (2007). Basic English Grammar for English language learners (Book 1). Irvine: Saddleback Educational Publishing.

Sudrajat, D. (2015). STUDI TENTANG PELAKSANAAN PENGAJARAN BAHASA INGGRIS DI SD KOTA TENGGARONG Didi. Cendikia, 9(1), 13-24.

Tiono, N. I., \& Yostanto, A. M. (2008). a Study of English Phonological Errors Produced By English Department Students. K@Ta, 10(1), 79-112. http://doi.org/10.9744/kata.10.1.79-112 